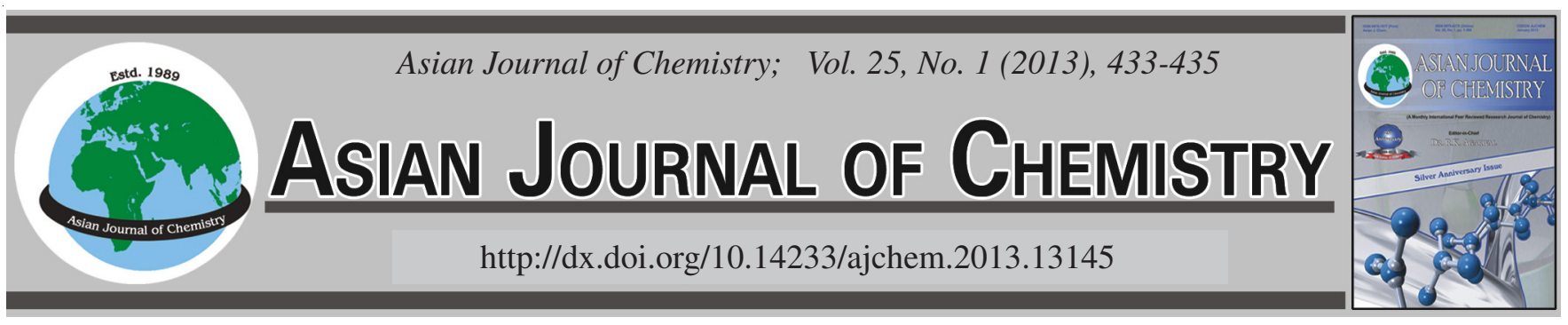

\title{
Water Extracts of Sapindus rarak as Medium/Reduction System for Silver Nanoparticles Formation
}

\section{Salprima Yudha S. ${ }^{1, *}$, Eka Angasa ${ }^{2}$, Reva Mariska $^{2}$ and John Hendri ${ }^{3}$}

${ }^{1}$ Laboratory of Bioinorganic Chemistry, Department of Chemistry, Faculty of Mathematics and Natural Sciences, University of Bengkulu, Jalan Raya Kandang Limun 38371A, Bengkulu, Indonesia

${ }^{2}$ Department of Chemistry, Faculty of Mathematics and Natural Sciences University of Bengkulu, Jalan Raya Kandang Limun 38371A, Bengkulu, Indonesia

${ }^{3}$ Department of Chemistry, Faculty of Mathematics and Natural Sciences, Lampung University, Jalan Soemantri Brojonegoro No. 1, Bandar Lampung, Indonesia

*Corresponding author: Fax: +62 736 20919; Tel: +62 736 20919; E-mail: sp.yudha.s@ gmail.com

\begin{abstract}
Silver ion was transformed into silver metallic form easily at room temperature using Sapindus rarak water extract. It take a few minutes to form silver nanoparticles even at room temperature. The formation of silver nanoparticles was explained in terms of the strength interaction of the silver ions with the compounds that available in the extract such as saponins, phenol and flavonoid derivatives. The UVVIS spectrophotometry analysis shows a broad band near $400 \mathrm{~nm}$ as specific surface plasmon resonance of the silver nanoparticles. The TEM analysis revealed the average size of the nanopraticles under current condition was about $50 \mathrm{~nm}$.
\end{abstract}

Key Words: Silver nanoparticles, Reduction, Sapindus rarak.

\section{INTRODUCTION}

The use of organism as raw materials for foods, drugs precursor, medicine, polymer and biomaterials widely known ${ }^{1}$. Increasingly the awareness towards green chemistry and other biological processes has a lead to develop an eco-friendly approaches. One of them is the utility of the natural products for advanced materials synthesis by either intracellular or extra cellular system e.g. synthesis of metal nanoparticles ${ }^{1,2}$. Based on the reason that the hazardous effects of organic solvents, reducing agents and toxic reagents applied for synthesis of nanoparticles on environment, encouraged researchers to develop convenient methods for preparation of metal nanoparticles $^{3-5}$. It has already known that, the plants extract could be used as medium for synthesis of several metals nanoparticles. One of the most important metal nanoparticles is silver nanoparticles since they possesses an excellent biocompatibility and low toxicity. Furthermore they have important applications such as antibacterial agents, DNA sequenching and several photonic applications ${ }^{6-8}$.

The development of the silver nanoparticles synthesis using surfactants were reported. For instance, synthesis of silver nanoparticles by Sophorolipids ${ }^{9}$ and stabilized by Gemini surfactant ${ }^{10}$ are already known. Since common synthetic surfactants can have negative effects such as skin irritation, therefore, the trend towards natural and vegetablederived surfactant is becoming of a great of interest ${ }^{11}$. Although there is one report on the use of soapnut for silver nanoparticles formation, no specific species was reported and the current reaction conditions are diffeent with the reported one ${ }^{12}$. In this report, we would like to explain the utility of the Sapindus rarak water extracts as a medium as well as reducing agent of the silver ions to form silver nanoparticles. The Sapindus rarak or well known as soapnuts contain saponins, which are a natural surfactant ${ }^{13}$. The plant extracts have been used for washing clothes by Asia native peoples. On the other hand, the soapnuts was also used in folk remedies as a contraceptive, excessive salivation, epilepsy and to treat chlorosis and migraines and even for to improve animal production ${ }^{14}$. The presence of the essential compounds in the water extract could be used as a a reducing or capping agent in thes silver nanoparticles synthesis.

\section{EXPERIMENTAL}

All analytical reagents and media components were purchased from Sigma-Aldrich and Merck. Deionized-double distilled water was used. The Sapindus rarak samples were collected in Talo, Province of Bengkulu, Sumatera island, Indonesia. The samples washed with deionized water and the rind was separated for the next procedures. 
Sapindus rarak rinds extract was prepared by boiling of $50 \mathrm{~g}$ of fresh Sapindus rarak for $10 \mathrm{~min}$, after which filtrated to get the clean rinds extract. $0.01 \mathrm{M}$ aqueous $\mathrm{AgNO}_{3}$ solution was added to $2 \mathrm{~mL}$ of rinds extracts. The reduction of silver ions was monitored by taking photograph of the solution every $5 \mathrm{~min}$ and measuring the absorbance of the reaction mixture in a range of wavelength from 200 to $750 \mathrm{~nm}$ using UV-VIS spectrophotometer to find characteritic of silver nanoparticles band. TEM measurements were performed on a JEOL JEM 1400 instrument operated at an accelerating voltage of $120 \mathrm{kV}$. Samples for TEM studies were prepared by placing drops of the silver nanoparticle solutions in samples 1-4 on carbon-coated TEM grids.

\section{RESULTS AND DISCUSSION}

The soapnut rind was separated from the seed as shown in Fig. 1b. The rinds were introduced to water and boiled for $10 \mathrm{~min}$. The extract was cooled to room temperature and subsequently kept at $4{ }^{\circ} \mathrm{C}$.
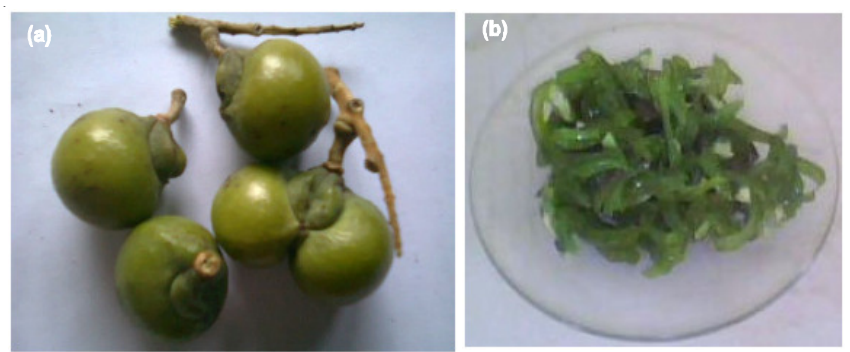

Fig. 1 Sapindus rarak

The extract was used as a medium and reductor for the formation of silver nanoparticles. When the $\mathrm{AgNO}_{3}$ solution was subjected to Sapindus rarak water extract, the biosynthesis reaction started within few minutes and the colour reaction was observed in which clear $\mathrm{AgNO}_{3}$ solution changed into yellow colour and finally to brown colour which indicates that formation of corresponding silver nanoparticles. Briefly, Fig. 2 shows the colour change (for 5-25 min) after addition of $\mathrm{AgNO}_{3}$ 0,01 to the Sapindus rarak water extract.

\begin{tabular}{|c|c|c|c|c|c|}
\hline $\begin{array}{l}\text { Before addition of } \\
0.01 \mathrm{M} \mathrm{AgNO}_{3}\end{array}$ & $\begin{array}{c}5 \text { minutes } \\
\text { After addition } \\
\mathrm{AgNO}_{3}\end{array}$ & $\begin{array}{c}10 \text { minutes } \\
\text { After addition } \\
\mathrm{AgNO}_{3}\end{array}$ & $\begin{array}{c}15 \text { minutes } \\
\text { After addition } \\
\mathrm{AgNO}_{3}\end{array}$ & $\begin{array}{c}20 \text { minutes } \\
\text { After addition } \\
\mathrm{AgNO}_{3}\end{array}$ & $\begin{array}{c}25 \text { minutes } \\
\text { After addition } \\
\mathrm{AgNO}_{3}\end{array}$ \\
\hline$\angle 3$ is & 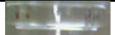 & & 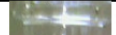 & $x+x=$ & \\
\hline 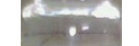 & $\Delta$ & & 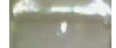 & $=$ & \\
\hline $0.01 \mathrm{~N}$ & $0.01 \mathrm{~N}$ & $0,01 \mathrm{~N}$ & $0.01 \mathrm{~N}$ & $0.01 \mathrm{~N}$ & 0,01 \\
\hline $5=$ & & & 1 & & \\
\hline
\end{tabular}

Fig. 2. Colour change due to the formation of silver nanoparticles

Spectrophotometric analysis of the Sapindus rarak water extract shows that no peaks at 390-430 nm (Fig. 3). The colour changes showed an evidence that the reaction of the compounds in the solution with silver ions to form silver nanoparticles. To get more evidences, the solution of the extracts after addition of the $0.01 \mathrm{M} \mathrm{AgNO}_{3}$, small aliquot of solution is used for the UV-VIS spectroscopy and the analysis shows a broad band at 390 to $410 \mathrm{~nm}$ (Fig. 4). The distinct peak shows a surface

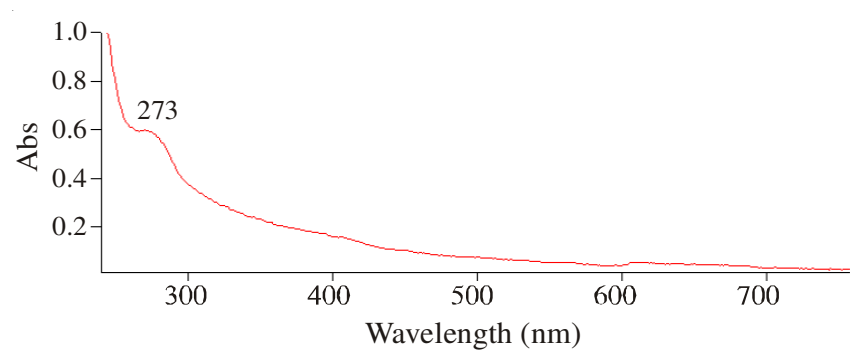

Fig. 3. UV-VIS patern of the Sapindus rarak soapnuts water extracts before addition of $\mathrm{AgNO}_{3}$ solution

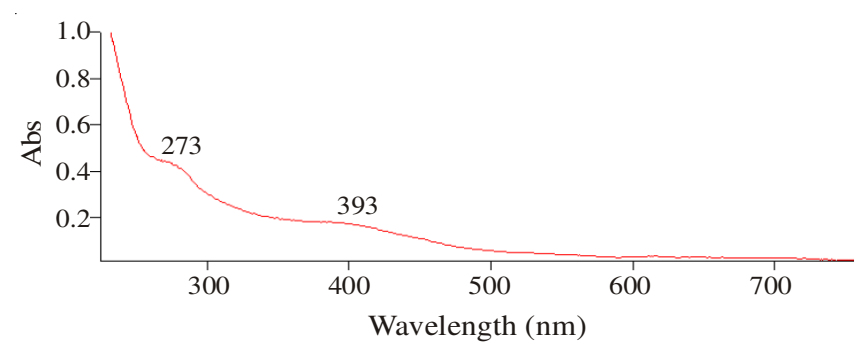

Fig. 4. UV-VIS patern of the Sapindus rarak soapnuts water extracts after addition of $\mathrm{AgNO}_{3}$ solution

plasmon resonance of the silver nanoparticles and the band related to the formation of the silver nanoparticles in the solution.

According to the transmission electron micrograph, the morphology of the silver nanoparticles was observed and approximately spherical, in which the partially nanoparticles is in aggregated form (Fig. 5).
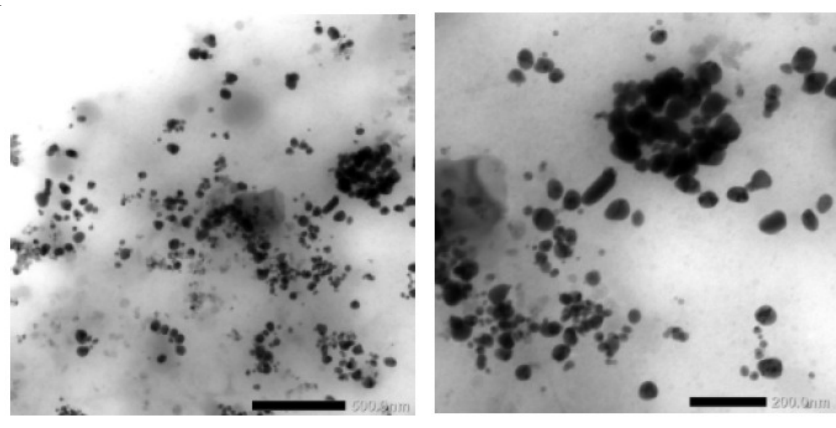

Fig. 5. TEM Patern of the silver nanoparticles

These results suggested that the silver nanoparticles are synthesized due to the action of plant extract, Sapindus rarak, which act as good bioreductor for biosynthesis of the silver nanoparticles. This result is especially remarkable taking into account that saponins are glycosides of hydrophobic alcohols that provide surface activity and form soap-like, foaming solutions in water. The presence of saponin is might responsible for the reduction of silver ions. On the other hand, the presence of flavonoid and phenol derivatives compounds in the extracts could also considered as active compounds as reductor of silver ions ${ }^{15}$.

According to the TEM micrograph and based on the calculation as shown in the histogram (Fig. 6), the nanoparticles sizes in range of 20-83 $\mathrm{nm}$ and particles distribution were 50.7 $\pm 14.53 \mathrm{~nm}$. 


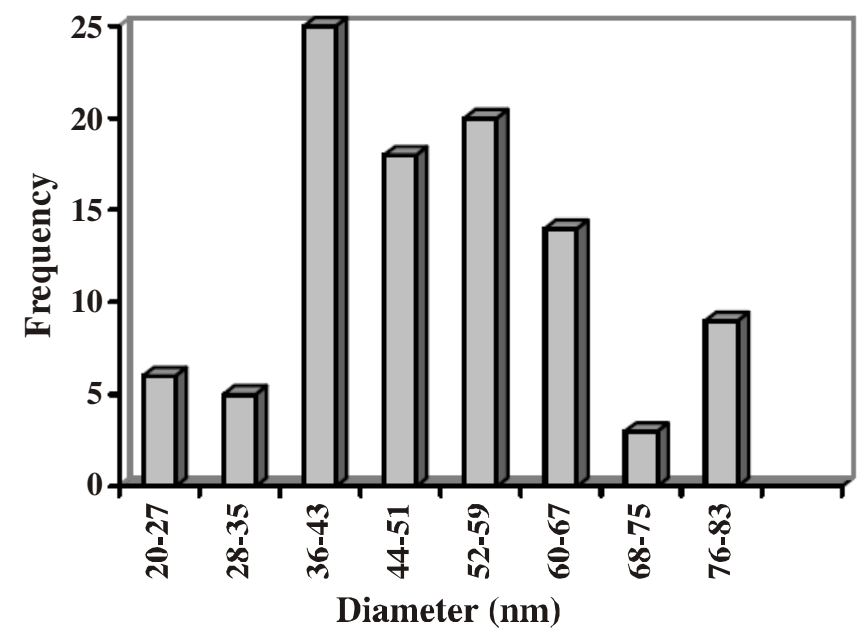

Fig. 6. Histogram of the silver nanoparticles

\section{Conclusion}

In summary, the Sapindus rarak water extracts was applied for synthesis of silver nanoparticles at room temperature and the produced nanostructures was characterized. The use of the current plant extract gives a new entry the utility of the bioresources as supporting agent for preparation of the advanced material.

\section{REFERENCES}

1. V. Kumar and S.K. Yadav, J. Chem. Technol. Biotechnol., 84, 151 (2009).

2. P. Raveendran, J. Fu and S.L. Wallen, J. Am. Chem. Soc., 125, 13940 (2003).

3. Y.M. Mohan, K.M. Raju, K. Sambasivudu, S. Singh and B. Sreedhar, J. Appl. Polymer Sci., 106, 3375 (2007).

4. K. Bar, D.K. Bhui, G.P. Sahoo, P. Sarkar, S.P. De and A. Misra, Colloids Surf. A, 339, 134 (2009).

5. M.N. Nadagouda and R.S. Varma, Green Chem., 10, 859 (2008).

6. E. Filippo, A. Serra, A. Buccolieri and D. Manno, J. Non-Crystalline Solids, 365, 344 (2010).

7. P. Gupta, M. Bajpai and S.K. Bajpai, J. Cotton Sci., 12, 280 (2008).

8. S.P. Chandran, S.P. Chaudhary, M. Pasricha, A. Ahmad and M. Sastry, Biotechnol. Prog., 22, 577 (2006).

9. M.B. Kasture, P. Patel, A. Prabhune, C.V. Ramana, A.A. Kulkarni and B.L.V. Prasad, J. Chem. Sci., 120, 515 (2008).

10. A. Akbarzadeh, Z. Davood, F. Ali, R.M. Mohammad, N. Dariush, T. Shahram, M. Majid and M.B. Nasim, Am. J. Appl. Sci., 6, 691 (2009).

11. X. Jian, H. Xia, L. Honglai and H. Ying, Colloids Surf. A, 273, 179 (2006).

12. M. Ramgopal, Ch. Saisushma, I.H. Attialla and A.M. Alhasin, Res. J. Microbiol., 6, 432 (2011).

13. T. Kummalue, P. Sujiwattanarat and W. Jiratchariyakul, J. Med. Plants Res., 5, 1087 (2011).

14. E. Wina, S. Muetzel and K. Becker, Asian-Aust. J. Anim. Sci., 19, 1580 (2006).

15. J.A. Jacob, H.S. Mahal, N. Biswas, T. Mukherjee and S. Kapoor, Langmuir, 24, 528 (2008). 